\title{
ENVIRONMENT AND SAFETY IMPACTS OF ADDITIVE MANUFACTURING: A REVIEW
}

\author{
Eva BURANSKÁ ${ }^{1}$, Ivan BURANSKÝ ${ }^{2}$, \\ Ladislav MOROVIČ ${ }^{2}$, Katarína LÍŠKA ${ }^{3}$ \\ ${ }^{1}$ SLOVAK UNIVERSITY OF TECHNOLOGY IN BRATISLAVA, \\ FACULTY OF MATERIALS SCIENCE AND TECHNOLOGY IN TRNAVA, \\ INSTITUTE OF INTEGRATED SAFETY \\ Ulica JÁNA BOTTU 2781/25, 91724 TRNAVA, SLOVAK REPUBliC \\ ${ }^{2}$ SLOVAK UNIVERSITY OF TECHNOLOGY IN BRATISLAVA, \\ FACULTY OF MATERIALS SCIENCE AND TECHNOLOGY IN TRNAVA, \\ INSTITUTE OF PRODUCTION TECHNOLOGIES, \\ Ulica JÁNA BOTTU 2781/25, 91724 TRNAVA, SLOVAK REPUbliC \\ 3 JOHN VON NEUMANN UNIVERSITY \\ GAMF FACULTY OF MECHANICAL ENGINEERING AND IT \\ DEPARTMENT OF VEHICLE TECHNOLOGY \\ 6000 KECSKEMÉT, IZSÁKI STR. 10, HUNGARY \\ e-mail: eva.buranska@stuba.sk, ivan.buransky@stuba.sk, ladislav.morovic@stuba.sk, \\ liska.katalin@gamf.uni-neumann.hu \\ Received: 17.04.2019, Accepted: 14.06.2019, Published: 22.07.2019
}

\begin{abstract}
The paper is focused on additive manufacturing (AM) which is the process of producing objects from a three-dimensional (3D) model by joining materials layer by layer, as opposed to the subtractive manufacturing methodologies [1], directly from raw material in powder, liquid, sheet, or a filament form without the need for moulds, tools, or dies. The article demonstrates potential environmental implications of additive manufacturing related to the key issues including energy use, occupational health, waste and lifecycle impact. AM provides a cost-effective and time-efficient way to fabricating products with complicated geometries, advanced material properties and functionality. Based on this review, we identified that additive manufacturing will have a significant societal impact in the near future. A critical technical review of the promises and potential issues of AM is beneficial for advancing its further development.
\end{abstract}

\section{Key words}

Additive manufacturing, environment, safety, impact 


\section{INTRODUCTION}

Additive manufacturing (AM) is the process of producing objects from a three-dimensional (3D) model by joining materials layer by layer as opposed to subtractive manufacturing methodologies [1], directly from raw material in powder, liquid, sheet, or filament form without the need for moulds, tools, or dies. It is typically contrasted with subtractive or deformationbased manufacturing methodologies, such as conventional machining or forming processes. The term AM encompasses a broad variety of manufacturing technologies, which are used in a wide range of industries: from consumer electronics to aerospace and numerous examples of medical applications, such as, for example, dental implants and hearing aids [2, 3].

Additive Manufacturing (AM; or "3D [three-dimensional] printing") is an emerging technology, mature enough to receive significant attention in the manufacturing community, but new enough for its environmental impacts to be incompletely studied [4]. Given that manufacturing is responsible for roughly one third of the global greenhouse gas emissions [5], plus many other environmental impacts, it is important to measure manufacturing impacts and understand their origins. Quantifying which aspects of a manufacturing process cause the largest environmental impacts allows the factory managers and machine designers to prioritize actions for sustainability and measure their success. Such prioritization should improve the effectiveness and return on investment of environmental initiatives [4].

Additive manufacturing (AM) proposes a novel paradigm for engineering design and manufacturing, which has profound economic, environmental, and safety implications. The design freedom offered by this category of manufacturing processes and its ability to locally print almost each designable object will have important repercussions across society. While AM applications are progressing from rapid prototyping to the production of end-use products, the environmental dimensions and related impacts of these evolving manufacturing processes have yet to be extensively examined. Only limited quantitative data are available on how the AM manufactured products compare to the conventionally manufactured ones in terms of energy and material consumption, transportation costs, pollution and waste, health and safety issues, as well as other environmental impacts over their full lifetime. However, only part of the AM process taxonomy is yet documented in terms of its environmental performance, and most life cycle inventory (LCI) efforts mainly focus on energy consumption. From an environmental perspective, the AM manufactured parts can be beneficial for very small batches or in the cases where the AM-based redesigns offer substantial functional advantages during the product use phase (e.g., lightweight part designs and part remanufacturing). Important pending research questions include the LCI of the AM feedstock production, supply-chain consequences, and health and safety issues relating to AM [2].

\section{METHODS AND HISTORY OF ADDITIVE MANUFACTURING}

First introduced during the 1980s to serve the highly specialized needs of model making and rapid prototyping (RP), additive manufacturing (AM) alias 3D printing emerged as a versatile technology platform for computer assisted design (CAD) and rapid manufacturing. AM allows the production of customized parts from metals, ceramics, and polymers without the need for moulds or machining typical for conventional formative and subtractive fabrication [6].

In the same way that the development of digital 2D printing together with desktop publishing has revolutionized communication and information technology, the development of AM technologies in conjunction with the "Internet of things" has the potential to revolutionize computer-guided fabrication of both complex objects and multifunctional material systems. Whereas conventional fabrication is governed by processing constraints related to industrial 
mass production, AM is inherently agile enabling faster turnaround on design and manufacturing of customized objects tailored to meet the demands of individuals and specific applications. In literature, the terms additive manufacturing, rapid prototyping, layered manufacturing, solid freeform fabrication, 3D fabbing, and 3D printing are used more or less synonymously. While "additive manufacturing" is preferred by most engineers, the term "3D printing" is far more common particularly in the popular media. In this contribution, the terms "additive manufacturing" (AM) and 3D printing are both used to describe the same general manufacturing principle [6].

AM processes can be classified into three different categories depending on the status of the material used to create the artefact during the process such as powder based, liquid based and solid based [7], [8]. An overview is given in Fig.1.

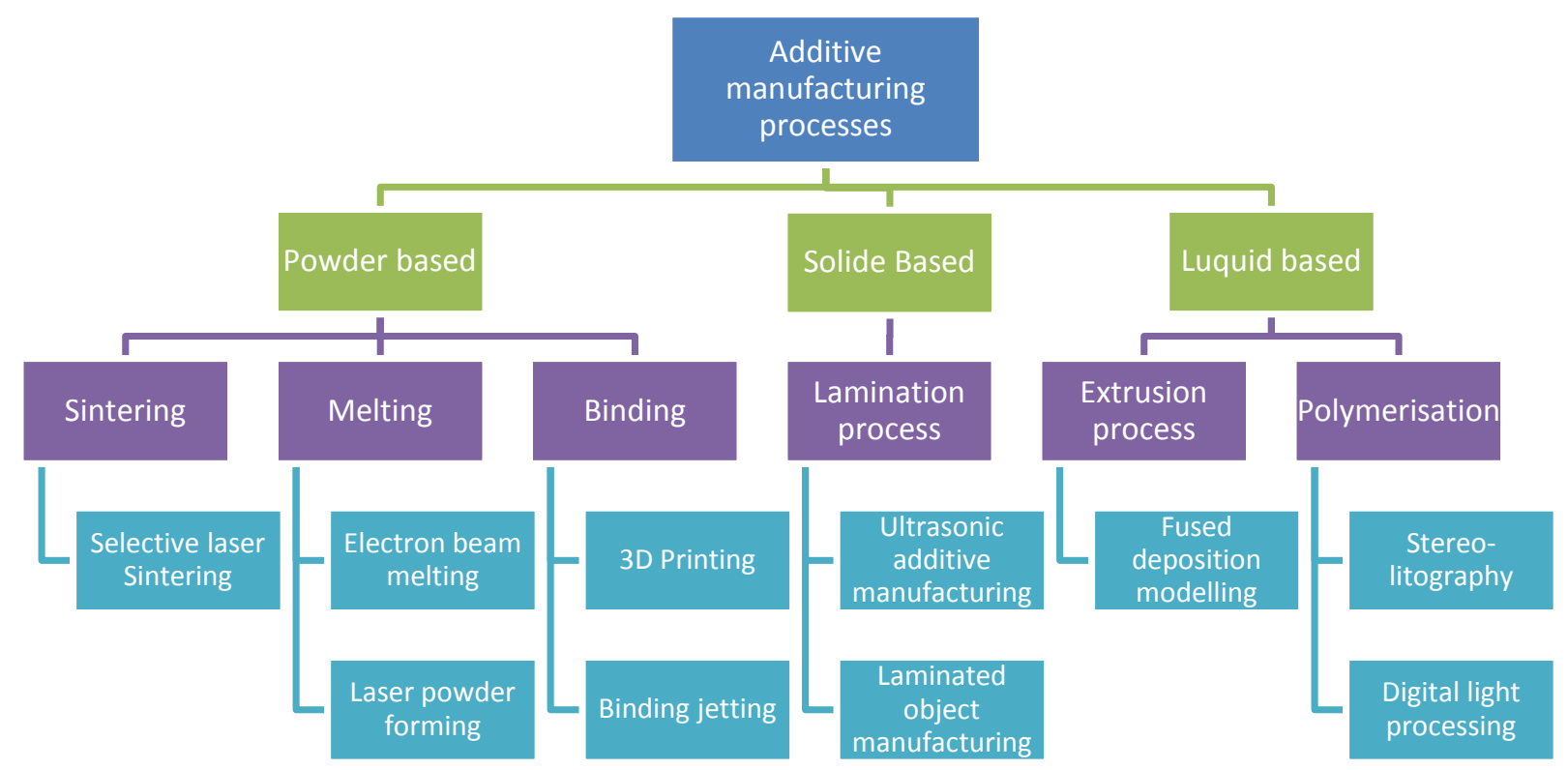

Fig. 1 Classification of additive manufacturing processes /modified from [7] and [8]

Selective laser sintering (SLS), electron beam melting (EBM), laser powder forming (LPF), and binder jetting (BJ) are applicable for metals, for prototype and direct part manufacturing purposes. LPF is applicable for repair of parts and can thus extend the lifetime of a product even further. BJ's ability to produce complex sand casting moulds has the potential of design optimisation, where less material would be used in the mould. Ultrasonic additive manufacturing (UAM) and laminated object manufacturing (LOM) are suitable for metal artefacts, whereas LOM is additionally considered suited for paper and plastic artefacts. Since adhesive is used between layers, very little residual stresses are left in the artefacts. UAM's ability for interchangeable metals during the layering process offers opportunities for the production and repair of metal material of more than one type, such as bimetals where different coefficient of thermal expansion are required [8].

Prototypical creations are mainly applied fused deposition modelling (FDM) for polymer based material and using stereo lithography (SL) and digital light processing (DLP) for photopolymer based material $[9,8]$.

Since the equipment for AM was usually very expensive and rare, hardly such technologies were used for non-industrial applications. Due to the emergence of low cost and easy to use so called 3D printers, this situation changed dramatically. In 2011, Bowyer et al. (2013) founded the RepRap project for low cost 3D printers, which were followed by likewise initiatives. The 
ability to manufacture in a highly flexible manner almost any geometric form in one step offers the chance to apply AM within households [8].

Today 3D printers are commercially available for less than $400 €$, enabling desktop fabrication of 3D objects even at home [6]. AM allows the production of 3D structures with high shape complexity. In the first step, CAD is used to create a virtual object, which is then digitally sliced. Objects with overhanging portions are designed with temporary support structures to prevent collapse during the build process. The coordinates of the virtual object and digital slices are then used to steer the motors, which control the position of the building device or the 3D-dispenser orifice, respectively. For practical purposes, this type of computer-aided manufacturing (CAM) is normally performed layer by layer with typical layer thicknesses ranging from 15 to $500 \mu \mathrm{m}$. When the layer thickness is below $50 \mu \mathrm{m}$, the naked eye will in most cases not be able to recognize the stair-steps associated with a layered manufacturing approach. For thicker layers or in demanding applications, postprocessing may be used to remove support structures or to improve surface properties [6].

\section{ENVIRONMENTAL IMPACT}

The research dealing with environmental impacts focuses on Life Cycle Assessment (LCA), is shown in Fig.2. Contrary to other methods of environmental impact assessment such as Carbon Assessment or Design for Environment, the LCA method enables to quantify accurately and with different criteria the environmental impact of a global system. This method of quantification has been standardized by two agencies: SETAC (Society of Environmental Toxicology and Chemistry) and UNEP (United Nations Environment Programme) under the ISO Standard 14044 [10].

In order to be as realistic as possible, a life cycle analysis has to be as exhaustive as possible. Then, it is necessary to take into account every steps of the whole life cycle of a product, from the extraction of raw material to the end of life step, including the manufacturing step. However, the latest step mentioned is generally left aside. In fact, few methods are able to evaluate precisely the environmental impact of existing manufacturing processes while the energy used to manufacture parts can be important and all the manufacturing processes do not have the same environmental impact. Owing to those remarks, it seems important to evaluate accurately the environmental impact during the manufacturing step [10].

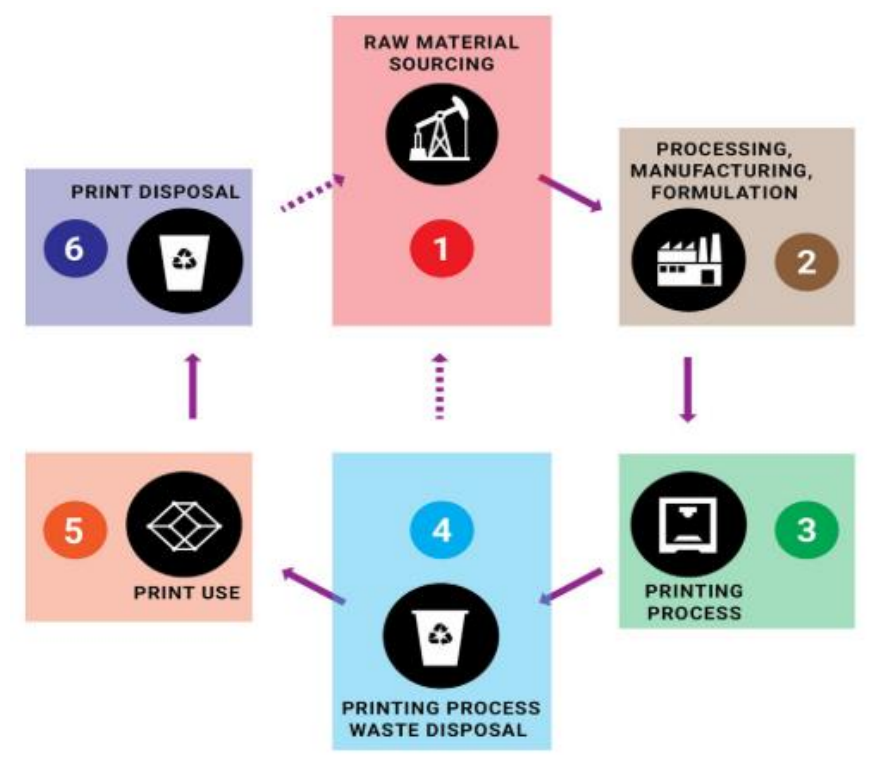

Fig. 2 Six stages of the additive manufacturing (AM) life cycle [11] 
In order to better examine the environmental implications of AM, the National Science Foundation (NSF) sponsored an NSF Environmental Implications of Additive Manufacturing workshop. The workshop reviewed the existing research on the environmental impacts of additive manufacturing (including energy and embodied energy), identified knowledge gaps and uncertainties that could help inform an agenda for future research into the environmental impacts of AM, and expanded the research community focused on environmental and energy use issues in AM [12].

Most of the available studies focus mainly on energy consumption. LCI data on resource consumption and direct or indirect process emissions are mostly not available. In general, the reported specific energy values for AM unit processes are 1 to 2 orders of magnitude higher compared to conventional machining and injection moulding processes [13].

Many researchers have been working towards this problem over the past 10-15 years and [14] discussed those and other important issues of ECM (environmentally conscious manufacturing) in their comprehensive reviews, containing over 300 references. Even though they did not address the environmental impacts of AM and tooling, they discussed a number of principles relevant to the subject. For example, environment-conscious production (ECP), environment-conscious design (ECD), materials recovery and recycling, product recovery and remanufacturing, as well as collection and disassembly, each play their role in the life cycle of the product processing via RP and tooling technologies. However, to date, the extent of the corresponding environmental impacts of the product processing lifecycle stages has not been fully quantified [15].

Drizo and Pegna [15] reviewed the state-of-the-art environmental impact assessment (EIA) of AM. A variety of methods were examined to measure environmental impact including lifecycle analysis (LCA), environmental impact scoring systems (EISS), and design for environment (DFE). They found that the scarcity of research and the rapid evolution of this technology left a large number of unresolved issues. The authors recommend a joint effort of process control engineers, designers, and environmental specialist to assess the impact [16].

Previous investigation of the environmental effects of AM have explored claims that the technology could reduce the carbon footprint of product through the reduction of transport and supply chain activities [11]. Other authors utilize such metrics to evaluate the impacts of the AM materials sourcing. Authors [17] present a valuable analysis on how to use LCAs to determine the environmental impact of sourcing chemicals in general. Most of these studies focus primarily on energy use or other factors. In Faludi and colleagues [18], this involved tracking all major impact types by comparing AM to machining of the hollowed-out thermoplastic parts, monitored from cradle to grave [19]. The main conclusion of the study was that, in contradiction to earlier hypotheses, the ecological impacts of transportation, disposal, and material concerns paled in comparison to the printer energy use for most printers. This would suggest that the highest priority for increasing the sustainability of AM would be to make 3D printers more efficient in their use of electricity. But, as printers become more efficient, the contribution of materials choices to overall ecological impacts and human health becomes much more significant, making analysis and comparison of impacts related to specific materials more important. We recommend performing LCA in accord with the International Organization for Standardization (ISO) Standards - ISO 14040:2006 and ISO 14044:2006 - to do such analyses [11].

AM holds a potential to reduce carbon footprint through the design optimization and reduction in the stream of material waste. The ATIKINS project concluded that an optimal design could show the weight and material savings of almost $40 \%$ [20]. Their analysis showed that, for a long range aircraft, reducing the weight of an aircraft by $100 \mathrm{~kg}$ results in both a 2.5 $\mathrm{m}$ dollars savings in fuel and a $1.3 \mathrm{Mt} \mathrm{CO}_{2}$ savings over the lifetime of the aircraft. It is clear that more work needs to be done to investigate the impact of AM on the environment. A systems 
approach which spans the cradle to grave life cycle of the AM fabricated component(s) is needed to capture the true benefits and possible pitfalls of using AM. It appears that components designed to exploit the unique weight savings characteristics of AM hold the greatest potential to reduce environmental impact [16].

Authors [21] presents a new methodology for the environmental impact evaluation, combined with a technical and economical assessment. This methodology is applied to the multiple additive manufacturing processes and will help manufacturers as a decision-making tool to make a choice of manufacturing process based on multiple criteria.

Study of authors [22] developed and tested novel materials for paste extrusion printing, and tested the materials invented by others. Testing compared their whole-system environmental impacts to the standard ABS extrusion, measured by the life cycle assessment (LCA); testing also assessed material strength, printability, and cost. Printing energy was reduced by $75 \%$ (from 160 to $40 \mathrm{Wh} /$ part), and the embodied impacts of materials were reduced by $82 \%$ (from 6.6 to 1.2 ReCiPe Endpoint $\mathrm{H}$ millipoints/part). Overall impacts per part were reduced by $78 \%$ (from 27 to $6 \mathrm{ReCiPe}$ Endpoint $\mathrm{H}$ millipoints/part), including the embodied impacts of the printer itself, in the maximum utilization scenario.

Additive manufacturing is thought to minimize material waste, but the actual material waste could be larger than expected, which is due to the human or printer errors [23]. In FDM, the quantity of support material is influenced by the part orientation and other settings of the printing. Additionally, failures may result from the insufficient preheating time, inappropriate geometry of parts, user error or printer malfunctions. Material waste from commercial FDM printers using ABS material in a heavily utilized open shop was collected in this study. The mass data of both support material and failed prints were recorded over time. In addition, the failed prints were classified into nine different categories and weighed according to failure reasons. The data were analysed and indicated that about $34 \%$ of the plastic used in the open studio was wasted. Only considering the failed prints as the extra amount of material consumed under realistic conditions, the mass of material lost to failed builds was about 2.22 times, what might be estimated in a controlled process study. The material waste and energy consumption could be combined to give a more comprehensive life cycle inventory of the commercial FDM printer.

\section{HEALTH AND SAFETY ISSUES RELATED}

The safety and health protection of employees at work is guaranteed by Art. 36 of the Constitution of the Slovak Republic and established by the system of legislation and other regulations to ensure health and safety at work.

$3 \mathrm{D}$ printing is transforming how products are made, but many legal issues such as the civil liability and intellectual property rights still need to be clarified. At the moment, there are no legal precedents regarding civil liability for products that were created by 3D printing. Manufacturers do not know what to expect. It is therefore up to us, to call on the European Commission to take a close look at the legal issues [24].

Many recent studies have confirmed the emission of particulates (including ultrafine particles as small as 1-3 nm) and volatile organic compounds (VOCs) from FDM [12], [25], and binder jetting processes [26] in office and lab settings.

The AM processes may pose new health problems. Therefore, it is important to investigate the toxicological and environmental hazards that may occur during handling, using, and disposing the materials used in various AM processes. These investigations can help achieve pollution prevention and reduction of occupational hazards and health risks. They may also prove to be a catalyst for greater acceptance of the AM industry [27]. 
Table 1 shows hazards associated with the printing process for extrusion based (FDM), powder based (LS) and photo polymerization (SL).

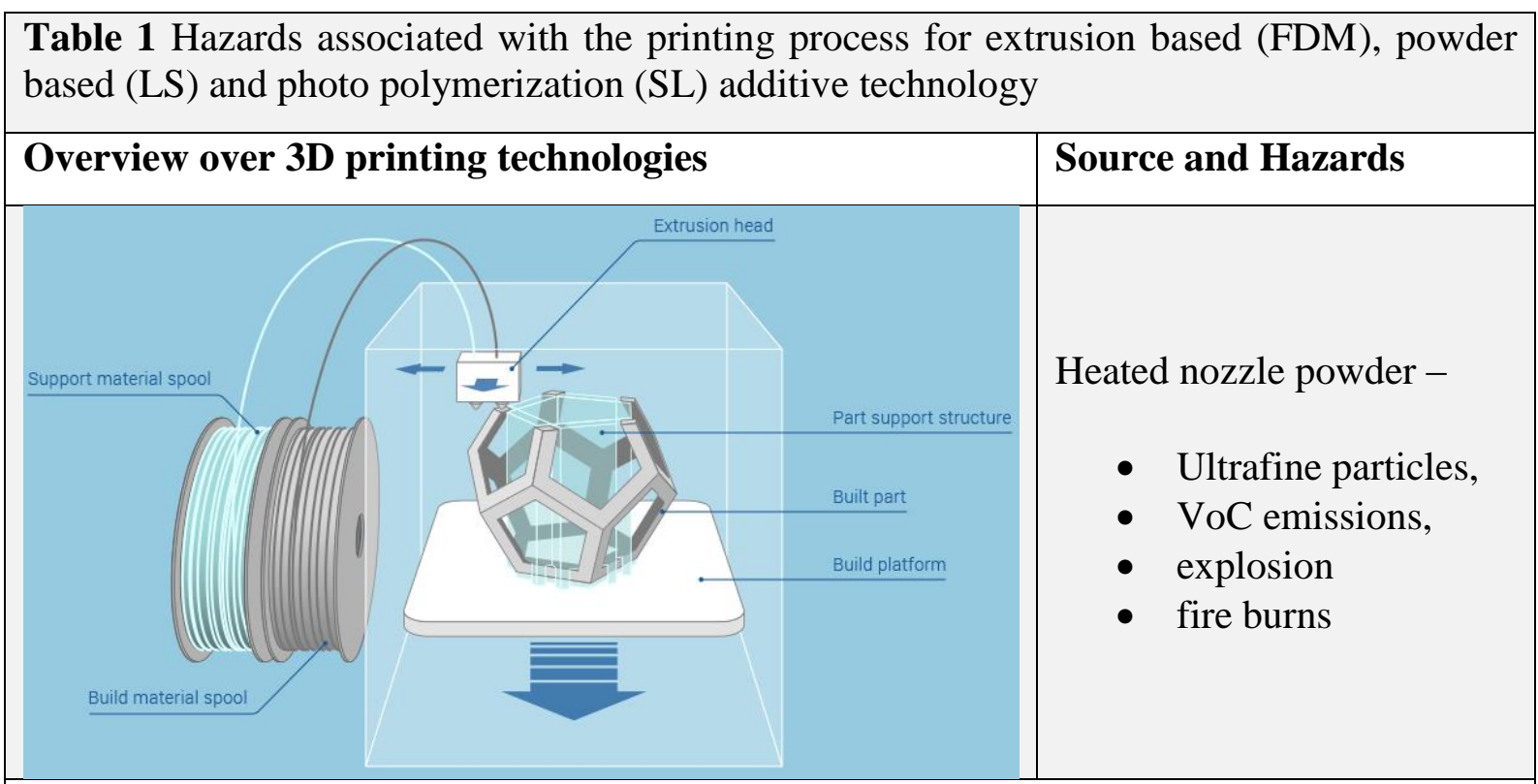

Fig. 3 Fused Deposition Modeling (FDM) [28]

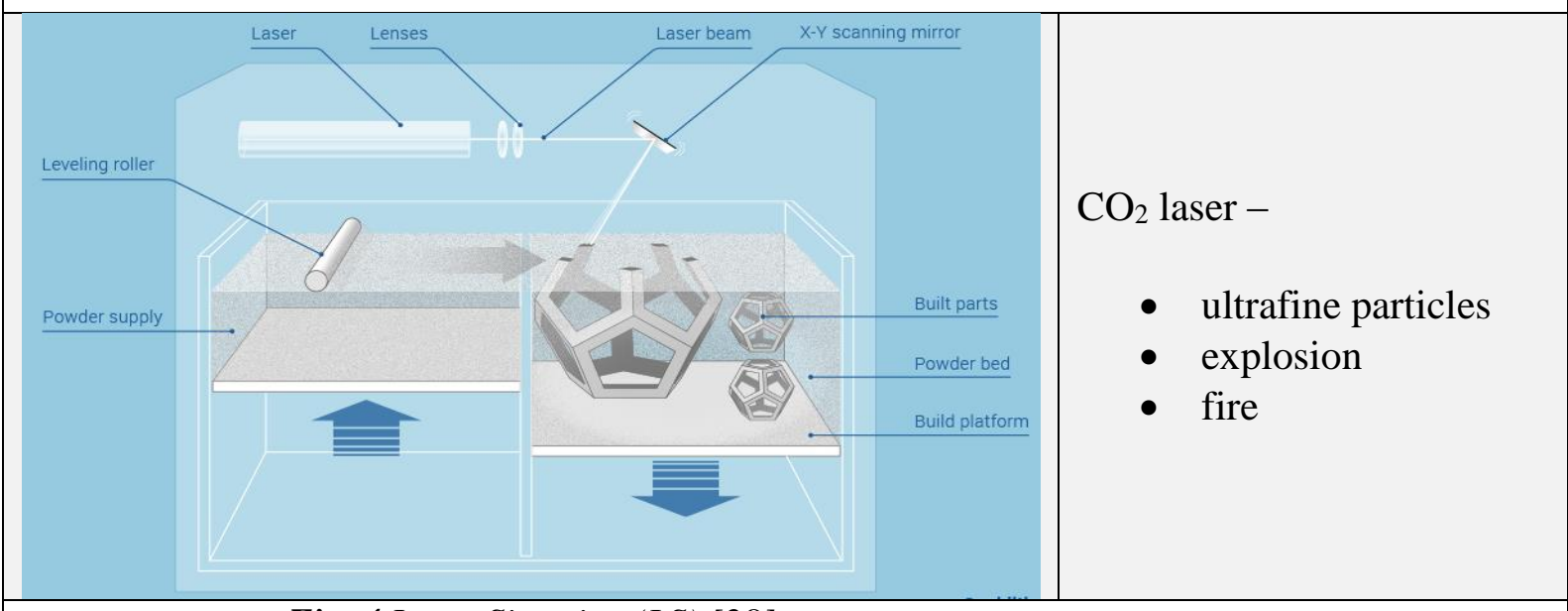

Fig. 4 Laser Sintering (LS) [28]

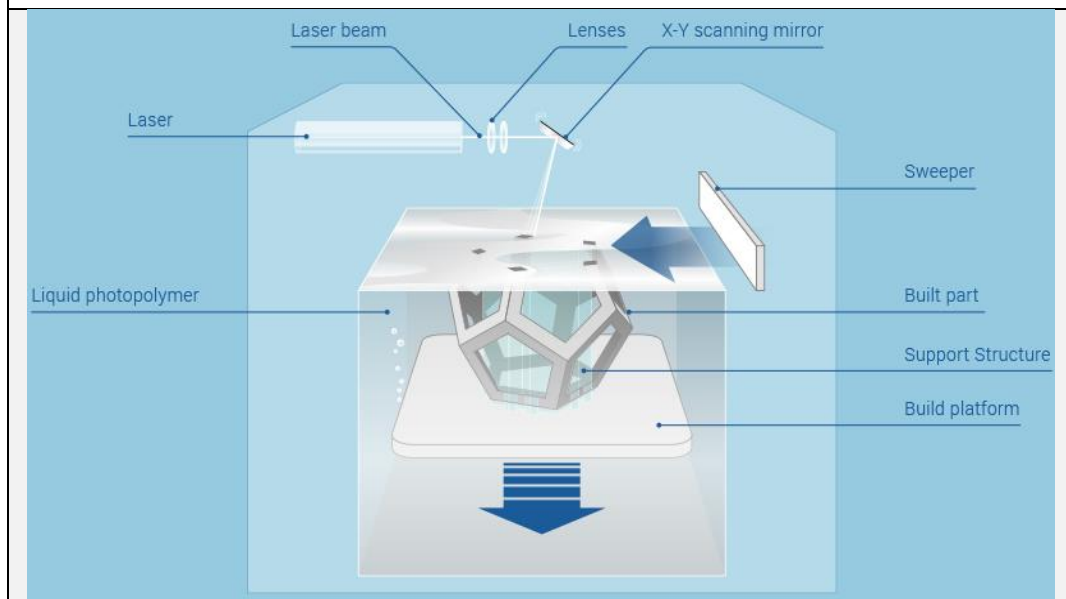

UV laser or projector-

- toxicity of compounds,

- $\quad$ solvents used to wash unreacted material

Fig. 5 Stereolithography (SL) [28] 
Various studies on the AM materials concluded that harsh skin reactions and eye irritation and allergies can occur when the operator comes in contact with these chemicals by either inhaling the vapours or if the materials accidently spill on the skin [15]. Prolonged exposure to these chemicals may lead to chronic allergies, though nothing can be said about whether they can be fatal. Since the majority of the chemicals are long-chain molecules, their biodegradability is very poor and the materials remain in the environment for extended periods of time. Poisonous gases like carbon di-oxide $\left(\mathrm{CO}_{2}\right)$, carbon monoxide $(\mathrm{CO})$, and nitrogen oxides are found to be emanated after the breakdown of these chemicals. It has also been predicted that noxious halocarbons $\left(\mathrm{CFCs}, \mathrm{HCFCs}, \mathrm{CCl}_{4}\right)$, trichloroethane $\left(\mathrm{CH}_{3} \mathrm{CCl}_{3}\right)$, nickel, and lead compounds might emerge from the operations of AM machines. Therefore, the environmental impact of the AM industry is a subject of great concern.

Even though some researchers [15] have acknowledged the need for standardization of raw materials in the AM industry, the potential toxicity, environmental hazards, and chemical degradability of solvents used for their removal still remain a topic of considerable research potential [27].

Along with the few harmful after effects of photopolymer liquid resin, not much is known about the effects of the solvents (propylene carbonate, tripropylene glycol monomethylether, isopropanol) used to dissolve support structures left after making prototypes in SLA. Nonetheless they are known to cause some symptoms like skin burns and respiratory uneasiness. AM machine operators need to be educated in handling and disposal of these materials along with the handling of high-intensity laser beams. Safety equipment like masks, goggles, and working gloves must obviously be provided in the work area. Slowly and steadily, AM processes will surely become safer and safer for the operators as new technological and safety features are developed and implemented in AM machines [27].

\section{RESULTS AND DISCUSSION ON RESULTS}

- The toxicological and environmental hazards as well as safety issues of AM are not well known at present and should be the focus of further research [2].

- Potential health problems can be found in severe eye and skin irritation as well as allergic skin reactions and inhalation risks. Therefore, proper dust collection and air ventilation as well as the use of protective gloves and safety glasses and masks is highly recommended [2].

- AM feedstock production processes are not well documented in terms of their environmental performance providing a highly relevant topic for future research [13].

A list of the current characteristics of AM is provided in Table 2, describing both the advantages of this manufacturing technology relative to the established subtractive and transformative methods, and the challenges to its development and wider adoption [29]. 
Table 2 Advantages and challenges of additive manufacturing [29] adapted from [30], [8], [27], [31], [32]

\begin{tabular}{l}
\hline Advantages \\
\hline Small batches of customised products are \\
economically attractive relative to traditional \\
mass production methods \\
- Direct production from 3D CAD models \\
mean that no tools and moulds are required, \\
so there are no switch over costs
\end{tabular}

- Designs in the form of digital files can be easily shared, facilitating the modification and customisation of components and products

- The additive nature of the process gives material savings, as does the ability to reuse waste material (i.e. powder, resin) not used during manufacture (estimated at 95 e $98 \%$ recyclability for metal powders)

- Novel, complex structures, such as free-form enclosed structures and channels, and lattices are achievable

- Final parts have very low porosity C Making to order reduces inventory risk, with no unsold finished goods, while also improving revenue flow as goods are paid for prior to being manufactured

- Distribution allows direct interaction between local consumer/client and producer

\section{Challenges}

- Cost and speed of production

- Changing the way and approach the designers take

- Removing the perception that AM is only for rapid prototyping and not for direct component and product manufacture

- Development and standardization of new materials $\mathrm{C}$ Validation of the mechanical and thermal properties of existing materials and AM technologies

- Development of multi-material and multicolour systems

- Automation of AM systems and process planning to improve manufacturing efficiency

- $\quad$ Post-processing is often required. This may be due to the stair stepping effect that arises from incrementally placing one layer on top of another, or because finishing layers are needed

- Support structure materials cannot be recycled so need to be minimised through a good build-up orientation

- Intellectual property issues, particularly regarding copyright

- Deficits in designers and engineers skilled in additive manufacturing

- Non-linear, localised collaboration with illdefined roles and responsibilities

- Continuously changing set of competitors the use of additive manufacturing

\section{CONCLUSION}

$\mathrm{AM}$ is a process of making parts from 3D model data. Usually, the parts are fabricated layer upon layer vice convention subtractive (e.g., machining, milling, etc.) means. There are a large number of diverse pieces of AM equipment commercially available, and their numbers continue to grow [16].

After 30 years of research and development, AM has evolved from a niche process for rapid prototyping to a legitimate manufacturing process for parts production [27]. Many companies are producing commercial parts using the AM process. For example, Boeing now has 200 different AM part numbers on 10 production platforms. The April 2012 issue of the Economist billed AM as the production technology of the future and called it "the third industrial revolution." It is highly likely that AM will have a significant societal impact in the near future.

If we look at it, it is very hard not to be amazed at how quickly the companies, facilities, materials and services related to AM arise. New applications are being developed, especially the production of components for final products. Low cost desktop 3D printers are gaining popularity, especially in the businesses and educational institutions. The foundations built over 
28 years, combined with the results of a number of new development activities point to a future that, in relation to the AM products and services from a global perspective, will soon be measured in tens of billions of euros.

$\mathrm{AM}$ is viewed as one of the most prominent technologies, with regard to which Europe can play a leading role; whereas the Commission recognised the benefits of 3D printing by sponsoring 21 projects based on the technology by Horizon 2020 between 2014-2016 [33].

We should not forget the effects of this rapid development of additive manufacturing on

the environment and safety. A critical technical review of the promises and potential issues of $\mathrm{AM}$ is beneficial for advancing its further development.

\section{Acknowledgements}

The article was written with the support of the Institutional Project "The use of Rapid prototyping technology on CNC machines".

\section{References}

[1] ASTM International, "F2792-12a - Standard Terminology for Additive Manufacturing Technologies," Rapid Manuf. Assoc., pp. 10-12, 2013.

[2] KELLENS, K., BAUMERS, M., GUTOWSKI, T. G., FLANAGAN, W., LIFSET, R., DUFLOU, J. R. 2017. Environmental Dimensions of Additive Manufacturing: Mapping Application Domains and Their Environmental Implications. J. Ind. Ecol., 21, pp. S49-S68.

[3] Wohlers, Wohlers report 2017:3D printing and additive manufacturing state of the industry: annual worldwide progress report., 22nd ed. FORT COLLINS, COLORADO, USA: Wohlers Associates, Inc., 2017.

[4] FALUDI, J., BAUMERS, M., MASKERY, I., HAGUE, R. 2017. Environmental Impacts of Selective Laser Melting: Do Printer, Powder, Or Power Dominate? J. Ind. Ecol., 21, pp. S144S156.

[5] PACHAURI, L. A., MEYER, R. K. 2014 Climate Change 2014: Synthesis Report. Contribution of Working Groups I, II and III to the Fifth Assessment Report of the Intergovernmental Panel on Climate Change. Geneva, Switzerland: IPCC.

[6] LIGON, S. C., LISKA, R., STAMPFL, J., GURR, M., MÜLHAUPT, R. 2017. Polymers for 3D Printing and Customized Additive Manufacturing. Chem. Rev., 117(15), pp. 10212-10290.

[7] KRUTH, J. P., LEU, M. C., NAKAGAWA, T. 1998. Progress in Additive Manufacturing and Rapid Prototyping. CIRP Ann., 47(2), pp. 525-540.

[8] CHEN, D., HEYER, S., IBBOTSON, S., SALONITIS, K., STEINGRÍMSSON, J. THIEDE, G.. 2015. Direct digital manufacturing: definition, evolution, and sustainability implications. J. Clean. Prod., Vol. 107, pp. 615-625.

[9] SALONITIS, K. 2014. Stereolithography. Compr. Mater. Process., pp. 19-67.

[10] Le BOURHIS, F., KERBRAT, O., HASCOET, J.-Y., MOGNOL, P. 2013. Sustainable manufacturing: evaluation and modeling of environmental impacts in additive manufacturing. Int. J. Adv. Manuf. Technol., 69(9-12), pp. 1927-1939.

[11] BOURS, J., ADZIMA, B., GLADWIN, S., CABRAL, J., MAU, S. 2017. Addressing Hazardous Implications of Additive Manufacturing: Complementing Life Cycle Assessment with a Framework for Evaluating Direct Human Health and Environmental Impacts. J. Ind. Ecol., 21, pp. S25-S36.

[12] REJESKI, D., ZHAO, F., HUANG, Y. 2018. Research needs and recommendations on environmental implications of additive manufacturing. Addit. Manuf., 19, pp. 21-28.

[13] KEllens, K., MERTENS, R., PARASKEVAS, D., DEWUlF, W., DUFlOU, J. R. 2017. Environmental Impact of Additive Manufacturing Processes: Does AM Contribute to a More Sustainable Way of Part Manufacturing? Procedia CIRP, 61, pp. 582-587.

[14] GUNGOR, A., GUPTA, S. M. 1999. Issues in environmentally conscious manufacturing and product recovery: a survey Askiner. Comput. Ind. Eng., 36, pp. 811-853. 
[15] DRIZO, A., PEGNA, J. 2006. Environmental impacts of rapid prototyping: an overview of research to date. Rapid Prototyp. J., 12(2), pp. 64-71.

[16] FRAZIER, W. E. 2014. Metal additive manufacturing: A review. J. Mater. Eng. Perform., 23(6), pp. 1917-1928.

[17] NARODOSLAWSKY, M., SHAZAD, K., KOLLMANN, R., SCHNITZER, H. 2015. LCA of PHA production - identifying the ecological potential of bio-plastic. Chem. Biochem. Eng. Q., 29, pp. 299-305.

[18] J. Faludi, C. Bayley, S. Bhogal, and M. Iribarne, "Comparing environmental impacts of additive manufacturing vs traditional machining via life-cycle assessment," Rapid Prototyp. J., vol. 21, no. 1, pp. 14-33, 2015.

[19] FALUDI, J., HOANG, T., GORMAN, P., MULVIHILL, M. 2016. Aiding alternatives assessment with an uncertainty-tolerant hazard scoring method. J. Environ. Manage., 182, pp. 111-125.

[20] ATKINS. ATKINS Project: a low-carbon manufacturing solution Project No: N0012J, 2009. [Online]. Available: http://www.lboro.ac.uk/service/publicity/newsreleases/2009/03_ATKINS.html. [Accessed: 02-Jul-2018].

[21] YOSOFI, M., KERBRAT, O., MOGNOL, P. 2018. Framework to Combine Technical, Economic and Environmental Points of View of Additive Manufacturing Processes. Procedia CIRP, 69, pp. $118-123$

[22] FALUDI, J., VAN SICE, C. M., SHI, Y., BOWER, J., BROOKS, O. M. K. 2019. Novel materials can radically improve whole-system environmental impacts of additive manufacturing. J. Clean. Prod., 212, pp. 1580-1590.

[23] SONG, R., TELENKO, C., WOODRUFF, G. W. 2016. Material waste of commercial FDM printers under realstic conditions. In: Solid Freeform Fabrication 2016: Proceedings of the 26th Annual International Solid Freeform Fabrication 2016: Proceedings of the 27th Annual International Solid Freeform Fabrication Symposium - An Additive Manufacturing Conference, pp. 1217-1229.

[24] BERGERON, J. 2018. 3D printing: sorting out the legal issues. European Parliament Spokesperson: Jaume Duch Guillot. [Online]. Available: http://www.europarl.europa.eu/news/en/headlines/economy/20180615STO05928/3d-printingsorting-out-the-legal-issues.

[25] STEPHENS, B., AZIMI, P., EL ORCH, Z., RAMOS, T. 2013. Ultrafine particle emissions from desktop 3D printers. Atmos. Environ., 79, pp. 334-339.

[26] AFSHAR-MOHAJER, N., WU, C. Y., LADUN, T., RAJON, D. A., HUANG, Y. 2015. Characterization of particulate matters and total VOC emissions from a binder jetting 3D printer. Build. Environ., 93(P2), pp. 293-301.

[27] HUANG, S. H., LIU, A., MOKASDAR, P., HOU, L. 2013. Additive manufacturing and its societal impact: A literature review. Int. J. Adv. Manuf. Technol., 67(5-8), pp. 1191-1203.

[28] Additively AG, Overview over 3D printing technologies 2018. [Online]. Available: https://www.additively.com/en/learn-about/3d-printing-technologies. [Accessed: 28-Jun-2019].

[29] FORD, S., DESPEISSE, M. 2016. Additive manufacturing and sustainability: an exploratory study of the advantages and challenges. J. Clean. Prod., 137, pp. 1573-1587.

[30]BERMAN, B. 2012. 3-D printing: The new industrial revolution. Bus. Horiz., 55(2), pp. 155-162, 2012.

[31] PETRICK, I. J., SIMPSON, T. W. 2013. 3D Printing Disrupts Manufacturing How Economies of One Create New Rules of Competition. Res. Technol. Manag., pp. 12-16.

[32] PETROVIC, L. P., GONZALEZ, V., FERRANDO, J.V.H., GORDILLO,O.J., J.D., PUCHADES, J.R.B., GRIÑAN. 2010. Additive layered manufacturing: sectors of industrial application shown through case studies. Int. J. Prod. Res., 49(4), pp. 1061-79.

[33] BERGERON, J. 2018. REPORT on three-dimensional printing, a challenge in the fields of intellectual property rights and civil liability (2017/2007(INI)). Brusel. 


\section{ORCID}

Eva Buranská

Ivan Buranský

Ladislav Morovič
0000-0002-2382-7508

0000-0002-7600-9007

0000-0001-7631-2631 